\title{
POR QUE PARTICIPAR DAS REDES SOCIAIS PARA PESQUISADORES?
}

\author{
Filipe Ferreira de Almeida Rego*
}

\author{
Autor para correspondência: Filipe Ferreira de Almeida Rego - filipefar@hotmail.com \\ *Doutor em Biotecnologia em Saúde e Medicina Investigativa pela Fundação Oswaldo Cruz. Professor \\ e coordenador da graduação em Biomedicina e Professor Colaborador do Programa de Planejamento \\ Ambiental da Universidade Católica do Salvador
}

Nos últimos anos o número de redes sociais aumentaram exponencialmente, assim como suas aplicabilidades. Estas novas aplicabilidades permitem classificar as redes sociais de diversas formas, dentre as quais, as redes sociais para melhoria da saúde'. Dentro destas redes sociais que objetivam melhorar a qualidade da saúde das pessoas, destacam-se as redes sociais criadas especificamente para pesquisadores, que aqui chamaremos de "Scientific Social Internet Network" (SSIN).

Dentre as SSIN que atualmente estão ativas, destacam-se: ResearchGate, ResearchID, ORCID, Academia.edu, BiomedExperts e Mendeley. Segundo um estudo realizado pela Nature, estas redes são conhecidas e utilizadas por milhões de pesquisadores, sendo o Research Gate a mais bem difundida ${ }^{2}$. Cada uma destas SSIN possui particularidades, entretanto todas possuem dois objetivos em comum: melhorar do fluxo de informações entre os pesquisadores e possibilitar colaborações entre as pessoas que participam da rede ${ }^{3}$.

A utilização destas SSIN possui muitas vantagens e limitações que vêm sido discutidas no meio aca dêmico, sendo as principais vantagens e desvantagens discutidas a seguir. Dentre as vantagens, a mais importante é a habilidade das redes sociais em intermediar e facilitar a colaboração entre pesquisadores, e consequentemente, melhorar a qualidade metodológica das pesquisas. Não seria melhor, para todas as instâncias envolvidas, se todos os pesquisadores de uma determinada área colaborassem?

Respondo esta pergunta sem receio de retaliações. Com certeza seria melhor para as agências de fomento, que, no Brasil, especificamente, nunca dispôs de muitos fundos. Por exemplo, entre 2001 e 2008, uma parcela de pesquisadores brasileiros estavam trabalhando para encontrar soluções para a epidemia de Dengue, onde foi observado, baseado nos artigos publicados, que muitos destes grupos de pesquisadores realizavam suas pesquisas isoladamente ${ }^{4}$. Estes trabalhos isolados, por eventual falha de comunicação entre as agências de fomento estaduais e federais, poderiam estar alocando recursos para se resolver $\circ$ mesmo problema. Neste ponto específico, as agências de fomento internacionais, como o Welcome Trust, já privilegiam trabalhos de forma colaborativa e que compartilham os dados com outros pesquisadores ${ }^{5}$.

Consequentemente, a realização de trabalhos da forma mais colaborativa possível, seria melhor para a sociedade, pois em termos de pesquisa no Brasil, são os principais patrocinadores através destas 
agências de fomento. Outrossim, estas colaborações, seriam melhor para a qualidade metodológica da pesquisa, tendo em vista que o olhar dos diversos pesquisadores ajudariam a identificar possíveis limitações e potencialidades do estudo. Entretanto, seria ingenuidade dizer que as SSIN serão as grandes responsáveis por estas colaborações, tendo em vista que o principal agente para que isto seja possível são os próprios pesquisadores, que por vezes, com seus egos inflados, renunciam participar de networks ou colaborar com alguns colegas.

A segunda vantagem que gostaria de ressaltar em relação a utilização das SSIN é a necessidade de publicizar os artigos e não apenas publicar ${ }^{6}$. Infelizmente a carreira de um pesquisador, para ser considerada bem-sucedida, passa por avaliações, avaliações estas, que podem ter como base diversos aspectos, como número de artigos publicados em um período, o fator de impacto das revistas nas quais os artigos foram publicados e a quantidade de citações, sendo este último a principal métrica utilizada atualmente ${ }^{7,8}$. Tendo em vista que a quantidade de citações é a principal métrica utilizada, foi demonstrado que os artigos publicados em SSIN, em particular na Academia. edu, tem o número de citações aumentados em $69 \%$ após 5 anos 9 , demonstrando que estas ferramentas são fundamentais para a melhoria das avaliações dos pesquisadores. Além disto métricas que analisam a quantidade de downloads e leituras dos artigos, também estão sendo utilizadas para avaliar os pesquisadores, e estas medidas podem ser facilmente encontradas em SSIN, como, por exemplo, o ResearchGate ${ }^{10}$.

Dentre os pontos negativos na utilização das SSIN, gostaria de destacar dois: a primeira e que mais me preocupa é se os pesquisadores realmente possuem tempo para realizar este tipo de atividade? Um estudo realizado recentemente revelou que os acadêmicos passam a menor parte de seu tempo realmente engajados na pesquisa, e uma parte considerável de seu tempo realizando tarefas administrativas, devido a isto, acredito que adicionar mais uma tarefa ao repertório de atividades de um pesquisador, poderia acarretar na perda de tempo para realização da pesquisa propriamente dita ${ }^{1}$. Por outro lado, como dito anteriormente, muitos pesquisadores já utilizam as $\mathrm{SSIN}^{2}$, então, o tempo para executar estas atividades talvez não onere consideravelmente os pesquisadores.

Um outro ponto negativo a ser discutido sobre a utilização das SSIN, questionado principalmente pelas editoras, é a quebra dos direitos autorais, onde alguns pesquisadores, que cederam os direitos para uma editora, principalmente por falta de informação, compartilham seus artigos sem consultar - contrato de transferências de direitos autorais. Entretanto, acredito que em um futuro não muito distante, todo o conhecimento gerado se tornará de acesso livre, acabando assim com algumas políticas de direitos autorais consideradas, eventualmente, abusivas.

No meu ponto de vista, considerando os pontos positivos e entendendo que os negativos não são completamente negativos, compreendendo que os pesquisadores, necessitam dessas redes para melhoria da qualidade do conhecimento produzido, tendo em vista que milhões de pesquisadores já utilizam estas SSIN, e na sociedade competitiva que vivemos, onde as agências nos avaliam constantemente, não restam dúvidas, as SSIN já fazem parte da pesquisa.

\section{REFERÊNCIAS}

1. Masic I, Sivic S, Toromanovic S, Borojevic T, Pandza $\mathrm{H}$. Social networks in improvement of health care. Mater Sociomed. $2012 ; 24(1): 48-53$. doi: $10.5455 / \mathrm{msm} .2012 .24 .48-53$

2. Van Noorden R. Online collaboration: Scientists and the social network. Nature. 2014;51 2(7513):126-9. doi: 10.1038/512126a

3. Bik HM, Goldstein MC. An Introduction to Social Media for Scientists. PLoS Biol. 2013;1 1(4). doi: 10.1371 /journal.pbio. 1001535

4. Morel CM, Serruya SJ, Penna GO, Guimarães R. Co-authorship network analysis: a powerful tool for strategic planning of research, development and capacity building programs on neglected diseases. PLoS Negl Trop Dis. 2009;3(8). doi: 10.1371/ journal.pntd.0000501 
5. Walport $M$, Brest $P$. Sharing research data to improve public health. Lancet. 2011 ;377(9765):537-9. 10.1016/S0140$6736(10) 62234-9$

6. Koohy H, Koohy B. A lesson from the ice bucket challenge: Using social networks to publicize science. Front Genet. 2014;5(430):1-3. 10.3389/ fgene.2014.00430

7. Van Noorden R. Metrics: A profusion of measures. Nature. 2010;465(7300):864-6. doi: $10.1038 / 465864 a$

8. Bollen J, Van de Sompel H, Hagberg A, Chute R. A principal component analysis of 39 scientific impact measures. PLoS One. 2009;4(6):1-10. 10.1371 /journal.pone.0006022

9. Niyazov $Y$, Vogel C, Price R, Lund B, Judd D, Akil $A$, et al. Open access meets discoverability: Citations to articles posted to Academia.edu. PLoS One. 2016;1 1(2):1-23. 10.1371/journal. pone. 0148257

10. Batooli Z, Ravandi SN, Bidgoli MS. Evaluation of Scientific Outputs of Kashan University of Medical Sciences in Scopus Citation Database based on Scopus, ResearchGate, and Mendeley Scientometric Measures. Electron physician. 2016;8(2):2048-56. doi: 10.19082/2048

11. Kiddy M. Under pressure. J Fam Heal. 2015;25(4):31-2 